\title{
A Photovoltaic Power Unit Providing Ancillary Services for Smart Distribution Networks
}

\author{
A. Filgueira Vizoso ${ }^{1}$, L. Piegari ${ }^{2}$, P. Tricoli ${ }^{3}$ \\ ${ }^{1}$ Industrial Engineering II Department, University of La Coruña \\ Avda. 19 de Febrero, 15405 Ferrol (Spain) \\ almudena@cdf.udc.es \\ 2 Department of Electrical Engineering, Politecnico di Milano \\ Piazza Leonardo da Vinci 32, 20133 Milan (Italy) \\ luigi.piegari@polimi.it \\ ${ }^{3}$ Department of Electrical Engineering, University of Naples Federico II \\ Via Claudio 21, 80125 Naples (Italy) \\ ptricoli@unina.it
}

\begin{abstract}
This paper deals with grid-connected photovoltaic (PV) power plants for supplying ancillary services to the distribution grid. The power converter, interfacing the photovoltaic system with the grid, can be controlled in order to achieve both the primary goal of power generation and the chosen ancillary services. In particular, in the paper, a power converter configuration with an opportune control algorithm is suggested; they make the photovoltaic system capable of generating the maximum power available from the solar source and, at the same time, capable of contributing to the voltage regulation of the grid and to the suppression of the current harmonics absorbed by loads close to the system. The control strategy is then applied to a sample grid-connected PV unit, simulated in Matlab Simulink environment. Numerical results, showing the effectiveness of the proposed solution, are reported.
\end{abstract}

\section{Key words}

Photovoltaic power systems, maximum power point tracking, ancillary services, voltage regulation, harmonic suppression.

\section{Introduction}

The reliability and security of electrical power systems require usually ancillary services, such as reactive power support, power quality, spinning reserves, energy balancing and frequency regulation. In a deregulated power system market, the responsibility of maintaining the correct operations of the system is basically attributed to the System Operator, that, hence, purchases these services directly from the generators [1]. Since the support of the power system with an ancillary service implies a reduction of the active power supplied to the grid, a financial compensation should be given to the provider by the System Operator. Moreover, the ancillary service supplied should be the most appropriate for the technical characteristics of the generator. In the case of generation with switching power converters, which is the case of most of the renewable energy generators, the more suitable ancillary services are the voltage regulation and the harmonic suppression [2]. In particular, the photovoltaic (PV) generation system, being connected to the grid by means of a voltage-source inverter (VSI), can provide reactive power anytime the power available from the source is lower than the maximum one. This eventuality happens for many hours during the day. In this way it can participate in voltage regulation without additional costs. The amount of necessary reactive power should be given by the system operator or, in alternative, can be derived from the PV system by measuring the voltage at its node. In the last situation the reactive power requested by loads connected at the same node of the PV unit can be realized without any signal from the network. At the same manner, the PV generation unit can be used to compensate current harmonics measured on the grid. In this way, all the harmonics due to loads connected at the same node of the PV system can be suppressed without significant additional costs in the interface converter.

The possibility of using renewable energy sources also for providing ancillary services appeared only recently in the technical literature, because switching power converters are normally devoted to regulate the injection of power into the grid in order to maximize the energy delivered by the renewable source. In case of wind turbines, the ancillary services proposed have been the compensation of reactive power [3] and the governor response [4]. Also some controls for harmonic compensation have been 
proposed, though the renewable source considered is generic and no comments are reported in the proper selection of the active power reference for each specific technology $[5,6]$. The compensation of the harmonics of the grid current has been further improved by the repetitive-based control for voltage source inverters [7], that is able to compensate only selected harmonics. Thereafter, this control has been applied to PV arrays connected in parallel to the network to provide ancillary services. However, PV systems usually are controlled by maximum power point tracking (MPPT) algorithms. Double-stage grid-connected PV converters have proven to be better than single-stage inverters since a better control of each PV module/string is achieved and the inverter stage may be based on a standard technology [8]. However, the dynamic interactions among the DC-DC and DC-AC stages and the MPPT controller may reduce the system performances. In the case of Perturb \& Observe (P\&O) algorithms, a wide-bandwidth analog control network can be used for matching quickly the power generated by the PV source with that supplied to the AC grid and reducing the influence of the grid voltage harmonics on the inverter DC-bus. The MPPT controller has not to act directly on the duty-cycle of the DC-DC stage, but it provides, by means of a compensation network, a proper reference voltage which must be followed by the PV array [9]. For the best of the knowledge of the authors, a control algorithm for dual stage converters, dedicated to the power generation from PV and integrated with a power quality conditioner, has not been proposed in the technical literature yet. The control suggested in this paper achieves both the MPPT function and the ancillary services of voltage regulation and current harmonic suppression. The paper discusses the performances obtained by the PV generator both at steady-state and during irradiation changes. The control strategy is finally tested by means of numerical simulations based on data of a real PV generator.

\section{System Configuration}

Photovoltaic arrays generate power in DC. In order to supply energy to the grid, an intermediate switching power converter is needed. In this study, a double-stage converter is used, made of a boost DC-DC converter in cascade to a space vector modulated (SVM) inverter. The inverter is connected to the AC power by means of a transformer, that guarantees electrical insulation between PVs and mains, and a LCL filter, that reduces harmonic content given by the space vector modulation of the inverter. Some papers published in the technical literature proved that LCL filter achieve better performances than those of traditional L filters. The detailed procedure for the selection of filter elements is presented in [10]. Following this procedure, the inductance $L_{1}$ can be selected on the basis of the current ripple desired on inverter side. If the transformer is specifically built for PV generation, this inductance is not actually present in the filter because it is the leakage inductance of the transformer itself. The capacitance $C$ is usually sized as a percentage of the equivalent impedance seen at full load. The inductance $L_{2}$ is evaluated on the basis of the resonant frequency of the LCL filter. This is usually placed in a range between ten time the grid frequency and one-half of the inverter switching frequency. This choice is a good compromise between the necessity to have the cutoff frequency above grid frequency and below the switching frequency. The damping resistance is finally selected on the basis of the desired filter efficiency, usually greater than $99 \%$.

A load absorbing distorted currents at low power factor is connected to the same node of the PV system. This load is typically constituted by some different loads connected in parallel. The low power factor is due to ohmic-inductive loads whereas the harmonic distortion is mainly caused by power electronics. In particular, diode rectifiers represent a diffused class of loads that introduces a very high harmonic content in the source current. So, in order to show that the system is capable of compensating the reactive power and reducing the harmonic distortion, a load constituted by a RL load in parallel to a diode rectifier has been simulated. A schematic of the PV plant simulated in this paper is shown in Fig. 1.

PV arrays have been modeled by a voltage source controlled by their supplied current $[10,11]$; in particular the following law has been taken into account:

$$
v_{P V}=V_{T} \log \frac{I_{p h}-i_{P V}+I_{0}}{I_{0}}-r_{P V} i_{P V},
$$

where $I_{p h}, I_{0}, V_{T}$ and $r_{P V}$ are electrical parameters dependent on the solar irradiation. The parameters, for one panel, have been obtained by tests realized on a real PV panel, Aluminum Tedlar 125M36. The simulated electrical characteristic is reported in Fig. 2.

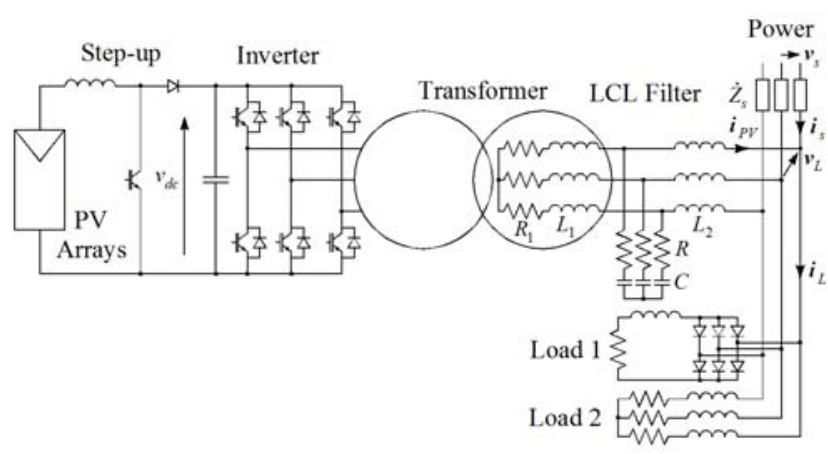

Fig. 1. Circuit configuration of grid-connected photovoltaic power plant

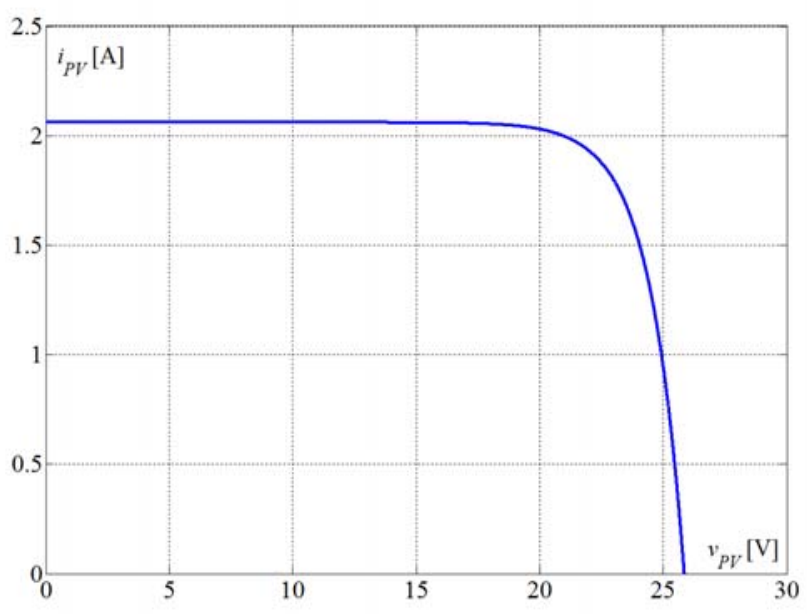

Fig. 2. Electrical characteristic of the PV panel used in the simulations 


\section{Control System}

The main goal of the system is the generation of the maximum allowable power given by the PV source. Moreover, as above mentioned, also the ancillary services of local voltage regulation and current harmonic compensation should be obtained. Therefore, the control system has to achieve the following tasks:

- PLL function to lock the grid voltage;

- MPPT algorithm to follow the maximum power point of the PV source;

- stabilization of the voltage on the inverter DC-bus;

- regulation of the $\mathrm{AC}$ rms voltage by means of the reactive power generated;

- compensation of the current harmonics injected by the local load.

The details of these functions are discussed in the following.

\section{A. PLL algorithm}

The PLL is necessary to watch the grid voltage and to establish the VSI output voltage in order to inject the desired active and reactive power. The PLL algorithm implemented is the traditional PLL for three phase networks [12]. In particular, the algorithm is derived on the rotating reference frame and the quadrature voltage is used as input for a PI regulator, in order to obtain the position $\varphi$ of the grid voltage space vector, $v_{L}$. In this way, the reference frame is oriented so that the space vector of the grid voltage presents only the direct component, i.e.:

$$
\tilde{\boldsymbol{v}}_{L}=\boldsymbol{v}_{L} e^{-j \varphi}=v_{d}+j v_{q}=v_{d} .
$$

The PLL is implemented using the positive sequence of the grid voltage in a way to eliminate the errors due to current harmonics.

\section{B. MPPT algorithm}

The MPPT algorithm has the goal of following the maximum power point of the PV panel when irradiation changes due to the variations of atmospheric conditions. In order to use an algorithm that results, at the same time, easy to be implemented and effective both at steady-state and during transients, a modified P\&O algorithm is used. The easy optimization can be achieved simply observing that the PV characteristic of a photovoltaic source has two very different slopes for voltages respectively lower and higher than the MPP. So, the PV characteristic is split in two regions: $v_{P V}<V_{M P P}$ and $v_{P V}>V_{M P P}$. In these regions two different perturbation amplitudes are used. In particular, big perturbations are used for $v_{P V}<V_{M P P}$ and small perturbations are used instead for $v_{P V}>V_{M P P}$. The implemented MPPT algorithm gives the PV voltage reference for the feedback chain controlling the boost converter.

\section{Stabilization of the DC voltage}

The main target of the control is to modify the output voltages of the converter in order that active and reactive powers follow actually their reference values. The VSI inverter regulates the active and reactive power flows. In order to optimize the control response, this regulation is made on the synchronous reference frame, whose position is given by the PLL above described.

Basing on the knowledge of the grid voltage space vector, the active and reactive power references can be easily transformed into direct and quadrature reference currents:

$$
\begin{aligned}
& I_{d, r e f}=\frac{2}{3} \frac{P_{r e f}}{v_{d}} ; \\
& I_{q, \text { ref }}=\frac{2}{3} \frac{Q_{r e f}}{v_{d}} ;
\end{aligned}
$$

where it has been taken into account that it is $v_{q}=0$ for the action of the PLL. The output reference signals of direct and quadrature components of the inverter voltages are obtained by means of two PI regulators. A feed forward action that takes into account the actual values of the grid voltages are used to speed up the regulators. Moreover, another feed forward block is used to decouple the direct and the quadrature components of the voltage. The control scheme to obtain the desired direct and quadrature component of the VSI is reported in [13].

The active power reference has to allow the injection on the grid of all the power generated by the PV system and, at the same time, has to ensure the optimal DC voltage level. For this reason, a regulator on the DC voltage could be capable of ensuring this function. However, in order to decouple the intervention of the inverter from the action of the boost converter connected to the PV panels, only a proportional regulator has been set up. A feed forward action giving the actual generated power gives the basic reference, whereas the proportional regulator ensures that the voltage keeps around the DC reference value. In Fig. 3 the control scheme to obtain the active and reactive power references is reported. In the figure, the superscript * indicates the reference quantities while the harmonic components are written with the diacritic mark $\sim$.

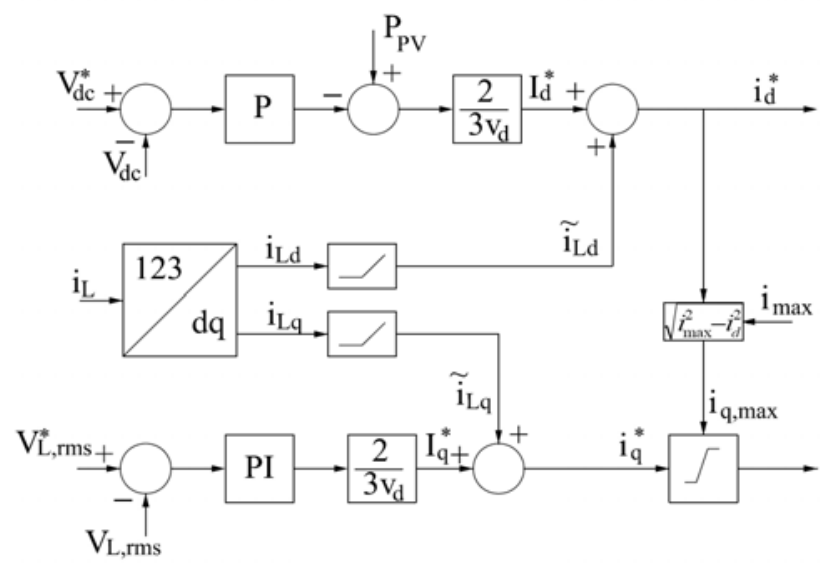

Fig. 3. Regulation control scheme

\section{Regulation of the AC rms voltage}

The reactive power reference is obtained by means of a PI regulator, controlling the rms voltage at the connection point (PCC) of PV system. However, the maximum allowable reactive power is obtained as a function of the actual active power generated. This is to avoid that the power converter can be overloaded during maximum insulation hours. Indeed, the VSI is typically sized on the maximum PV power and so it can supply reactive power 
only when the active power is lower than the maximum value. The reactive power producible is:

$$
Q_{\max }=\sqrt{A_{n}^{2}-P^{2}}
$$

where $A_{n}$ indicates the rated apparent power of the inverter and $P$ is the active power supplied.

\section{E. Compensation of the current harmonics}

In order to compensate for current harmonics, the current references in the rotating frames given by (3) has been corrected. In particular, the current absorbed by the load connected in parallel to the VSI, transformed into the rotating frame, is filtered by means of a high-pass filter. Direct and quadrature current harmonics are added to the reference signals obtained by (3) to supply these harmonics by means of the VSI.

\section{Numerical Simulations and Discussion}

In the case studied in this paper, the photovoltaic array is connected to a typical European low-voltage grid, having a rated voltage $V_{n}$ of $400 \mathrm{~V}$ and a frequency $f_{n}$ of $50 \mathrm{~Hz}$. The inverter is controlled by a SVM technique with a switching frequency $f_{s}=10 \mathrm{kHz}$.

Selecting an inverter harmonic suppression at the switching frequency equal to $1 \%$, the minimum required inductance $L_{1}$ is equal to $1.6 \mathrm{mH}$. Moreover, the following assumptions have been made:

- theoretical filter efficiency $\eta_{f}=0.9999$ without considering the losses of $R_{1}$;

- reactive power of filter capacitor equal to $1 \%$ of the rated active power delivered to the grid;

- resonant frequency equal to one-half of the switching frequency.

On the basis of these hypotheses, the parameters of the LCL filter are given in Table I. The presence of the resistance $R_{1}$ reduces the actual efficiency of the filter in rated conditions down to 0.98 . The inductance $L_{1}$ is the leakage inductance of the transformer. This is the reason why the short circuit voltage of the transformer is very high, as Table II shows.

Table I - Parameters of the LCL filter used

\begin{tabular}{|c|c|c|c|c|}
\hline $\mathrm{R}_{1}[\Omega]$ & $\mathrm{L}_{1}[\mathrm{mH}]$ & $\mathrm{L}_{2}[\mu \mathrm{H}]$ & $\mathrm{R}[\Omega]$ & $\mathrm{C}[\mu \mathrm{F}]$ \\
\hline 0.026 & 1.6 & 52 & 1.6 & 20 \\
\hline
\end{tabular}

Table II - Parameters of the transformer

\begin{tabular}{|c|c|c|c|c|}
\hline $\begin{array}{c}V_{n 1} / V_{n 2} \\
{[\mathrm{~V}]}\end{array}$ & $\begin{array}{c}S_{n} \\
{[\mathrm{kVA}]}\end{array}$ & $\begin{array}{c}f_{n} \\
{[\mathrm{~Hz}]}\end{array}$ & $\begin{array}{c}v_{c c \%} \\
{[\%]}\end{array}$ & $\begin{array}{c}\cos \varphi_{\mathrm{cc}} \\
{[-]}\end{array}$ \\
\hline $400 / 400$ & 150 & 50 & 47.2 & 0.022 \\
\hline
\end{tabular}

The simulated PV source has maximum power of about $100 \mathrm{~kW}$, whereas the open circuit voltage is about $380 \mathrm{~V}$. It is constituted by 160 modules connected in parallel. Each module is made of 15 panels connected in series and the characteristics of each panel are those reported in Section 2.

A numerical simulation has been set up to show the capability of the system of achieving the following goals:

- to supply the maximum active power available from the PV source;
- to regulate the $\mathrm{AC}$ rms voltage by injecting the suitable amount of reactive power;

- to regulate the DC voltage;

- to reduce the harmonic content of current supplied by the mains.

An ohmic-inductive load and a diode rectifier are connected in parallel to the PV system. The active and reactive power drawn by the linear load are $25 \mathrm{~kW}$ and $25 \mathrm{kVAr}$, respectively. The diode rectifier feeds a resistive load of $16 \Omega$, absorbing a mean power of about $18 \mathrm{~kW}$. The line connecting the feeder to the load and the PV system has the typical values of a distribution line, as reported in Table III. The supposed length of the line is 100 meters.

Table III - Parameters of the line and capacitance of the DC-bus
\begin{tabular}{|c|c|c|c|c|}
\hline $\begin{array}{c}\text { Rated } \\
\text { Voltage } \\
{[\mathrm{V}]}\end{array}$ & $\begin{array}{c}\text { Line } \\
\text { resistance } \\
{[\mathrm{m} \Omega / \mathrm{km}]}\end{array}$ & $\begin{array}{c}\text { Line } \\
\text { inductance } \\
{[\mathrm{mH} / \mathrm{km}]}\end{array}$ & $\begin{array}{c}\text { DC-bus } \\
\text { capacitance } \\
{[\mathrm{mF}]}\end{array}$ & $\begin{array}{c}\text { Line } \\
\text { length } \\
{[\mathrm{m}]}\end{array}$ \\
\hline 400 & 290 & 1.2 & 5.8 & 100 \\
\hline
\end{tabular}

At first, the PLL algorithm is executed until it locks the grid voltage. When the system works disconnected to the grid, the boost converter is disabled and the PV open circuit voltage is equal to the VSI input voltage (about $380 \mathrm{~V}$ ). At $t=0.5 \mathrm{~s}$, the circuit breaker is closed and the PV system is connected to the grid. The MPPT algorithm begins to operate when PVs are at their open circuit voltage. A maximum solar irradiance condition of $1000 \mathrm{~W} / \mathrm{m}^{2}$ is simulated, so the maximum generable power is about $100 \mathrm{~kW}$. The reactive power reference is obtained by means of a PI regulator trying to keep the AC rms voltage to $400 \mathrm{~V}$. Its value is saturated, however, to keep the inverter current to a value lower than $250 \mathrm{~A}$ (equivalent to $150 \mathrm{kVA}$ ). The active power reference is obtained by the PI regulator acting on the DC voltage. The reference value for the DC voltage is $1000 \mathrm{~V}$. This value has been chosen to allow the system to supply the required reactive power. At the time $t=2 \mathrm{~s}$, the irradiance is changed with a step to $0 \mathrm{~W} / \mathrm{m}^{2}$. This simulates the capability of the system of working also during nighttime in its functions of voltage regulation and harmonic compensation. When no active power is supplied, the inverter regulates the $\mathrm{AC}$ voltage by injecting only reactive power. After one second (at the time $t=3 \mathrm{~s}$ ) the irradiance is changed again to its maximum value with another step variation. It is worth to note that in this case the MPPT algorithm has to reach the MPP starting from zero voltage condition. As above discussed, in this side of the characteristic, the PV behavior is different and the transient is different too.

In Fig. 4 the active and reactive power supplied by the system are shown. It is clear that the active power reaches the MPP values both starting from the open circuit condition $(t<2 \mathrm{~s})$ and from the short circuit condition $(t>3 \mathrm{~s})$. The reactive power changes as a function of the supplied active power in order to control the AC rms voltage.

In Fig. 5 the $\mathrm{AC}$ rms voltage is reported. As is clear, the voltage is regulated at the desired value. It is worth to note also that, when the active power generated is maximum, the voltage at the PCC could be higher than $400 \mathrm{~V}$. For 
this reason the VSI draws reactive power by the network to regulate the $\mathrm{AC}$ rms voltage.

In Fig. 6 the inverter DC bus voltage is reported. The voltage is equal to the PV open circuit voltage until the breaker is closed. Then, the voltage is kept around $1000 \mathrm{~V}$ by the control system, also when the PV panel does not generate at all (between $t=2 \mathrm{~s}$ and $t=3 \mathrm{~s}$ ).

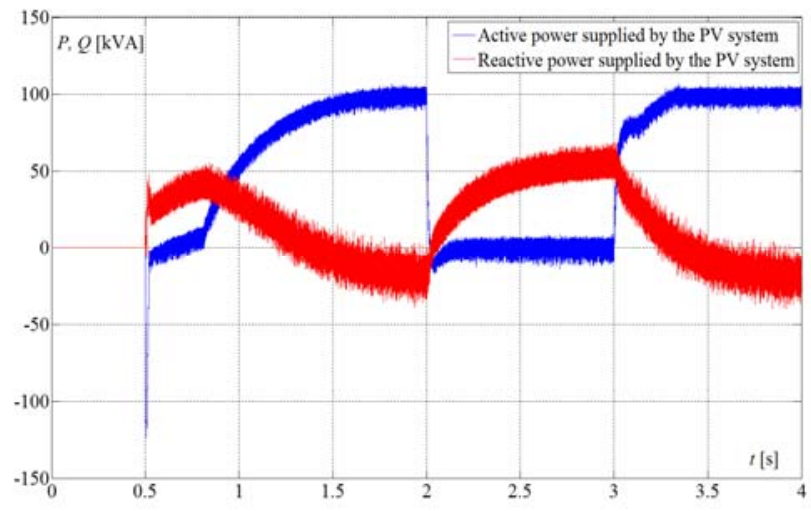

Fig. 4. Generated active and reactive powers during step changes of solar irradiance

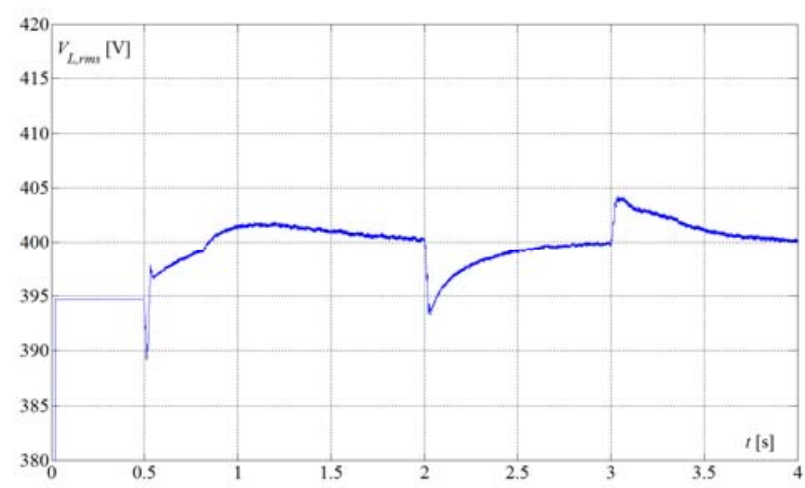

Fig. 5. Diagram of AC rms voltage

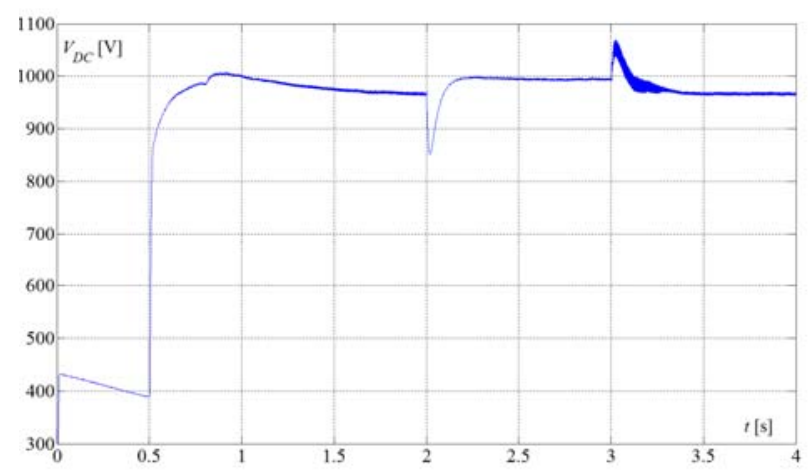

Fig. 6. Inverter DC-link voltage diagram during step changes of solar irradiance

In order to show the harmonic compensation action, in Figs. 7 and 8 the spectra of both the current supplied by the network and the current absorbed by the load are reported, respectively. In particular, the spectra in Fig. 7 refer to the condition of maximum active power $(100 \mathrm{~kW})$ delivered to the grid, whereas those in Fig. 8 refer to the condition of no active power (i.e. nighttime). The current harmonics supplied by the grid are lower than those drawn by the load, because of the compensating action of the PV unit. The THD in both cases is reduced by the suggested control as quantitatively shown in Table IV. However, from the analysis of the figures, it is clear that the compensation action is performed better when no active power is supplied. This is due to the limitation in the maximum apparent power that the VSI is capable of supplying, given by (4). As is clear from Figs. 7 and 8 the total harmonic content is lower in the case of no power supplied. However, the THD, as shown in Table IV, is almost the same. This is because the first harmonic, not plotted in the figures, is different in the two cases. In particular, when the PV supplies the maximum power, the current injected in the network has a first harmonic of 144 A while, when PV does not supply active power, the first harmonic of the current absorbed by the grid is $109 \mathrm{~A}$. These values depend on load conditions and change when load changes. In particular, when the load matches the PV power, the first harmonic supplied by the grid is very low and the THD can result very high also if the compensation action works correctly. For this reason, in order to understand the effect of the filter action, it is more appropriate to look at the total harmonic content rather than to evaluate the THD.

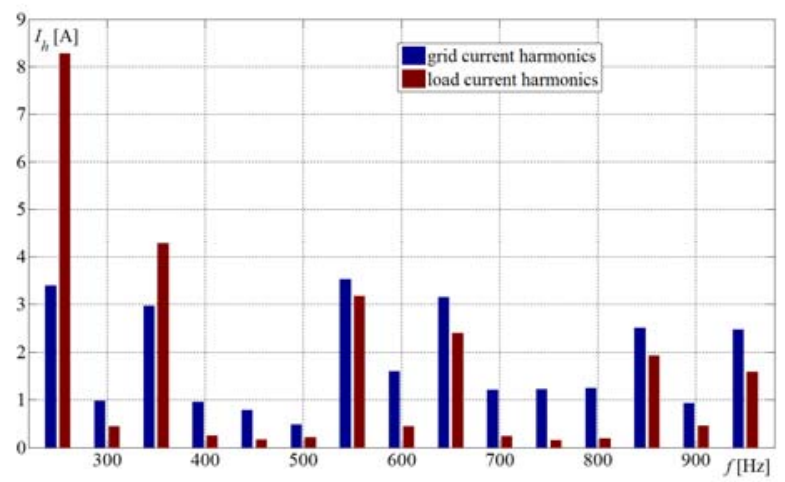

Fig. 7. Harmonics of currents supplied by the grid (blue) and absorbed by the load (red) when the PV system supplies maximum power

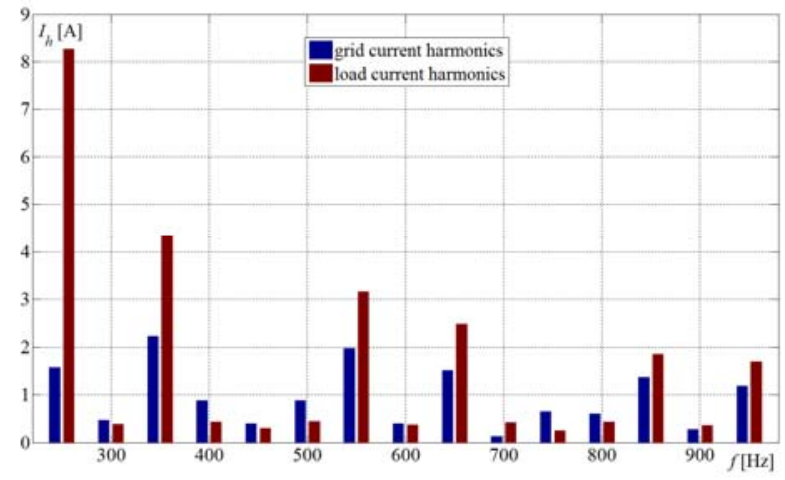

Fig. 8. Harmonics of currents supplied by the grid (blue) and absorbed by the load (red) when the PV system does not supply active power

Table IV - THD of grid and load currents

\begin{tabular}{|c|c|c|c|c|}
\hline & \multicolumn{2}{|c|}{ Maximum PV power } & \multicolumn{2}{|c|}{ Zero active power } \\
\hline THD & $\begin{array}{c}\text { Grid } \\
\text { current }\end{array}$ & $\begin{array}{c}\text { Load } \\
\text { current }\end{array}$ & $\begin{array}{c}\text { Grid } \\
\text { current }\end{array}$ & $\begin{array}{c}\text { Load } \\
\text { current }\end{array}$ \\
\cline { 2 - 5 }$[\%]$ & 7.5 & 10.6 & 7.3 & 10.8 \\
\hline
\end{tabular}

The current harmonics can be further reduced incrementing the inverter switching frequency, that would lead to a different design of the regulators with lower oscillations of the inverter output voltage. Conversely, an increase of the inverter VA rating could reduce the THD at full power. However, in this case the advantage 
obtained in terms of harmonic suppression is less significant, because it is related only to a higher maximum value of the quadrature current available, without the possibility of improving the dynamic of the control loop.

\section{Conclusions}

With the increasing diffusion of renewable energy sources, the problem of grid regulation arises also for distribution networks. In fact, these networks are no more passive networks, but they present both generators and loads. Thus, control strategies for voltage and frequency regulation should be realized for improving the quality of the service. Among renewable energy sources, PV sources represent a good opportunity to accomplish not only the generation goal, but also the voltage regulation one. As well known, the PV is a DC source and, therefore, needs a switching power converter for the connection to the main grid. The inverter can be used also for providing some ancillary services useful for the grid regulation. In this paper, the authors analyze the possibility of using PV sources to regulate $\mathrm{AC}$ voltage and to suppress current harmonics injected by loads connected at the node of the PV system. A control strategy for the power electronic converters is presented: the MPPT function on the PV source is achieved and, at the same time, the requested ancillary services are provided to the grid. The active power is controlled to maximize the power generated by the PV source, whereas the reactive power is controlled to compensate, when possible, the amount required by the loads connected to the node of the PV system. Moreover, the control of the converter is capable of reducing also higher harmonics of the current present in the grid. The proposed strategy has been tested by means of numerical simulations and the results show the effectiveness of the control proposed.

\section{References}

[1] K. Bhattacharya and J. Zhong, "Reactive power as an ancillary service", IEEE Trans. Power Syst., vol. 16, no. 2, pp. 294-300,May 2001.

[2] Jinn-Chang Wu and Hurng-Liahng Jou, "A new UPS scheme provides harmonic suppression and input power factor correction", in IEEE Trans. Ind. Electron., vol. 42, no. 6, pp.629-635, Dec. 1995.
[3] N.R. Ullah, K. Bhattacharya, and T. Thiringer, "Wind Farms as Reactive Power Ancillary Service Providers Technical and Economic Issues", in IEEE Trans. Energy Conver., vol. 24, no. 3, pp. 661-672, Sept. 2009.

[4] N.W. Miller, and K. Clark, "Advanced controls enable wind plants to provide ancillary services", in 2010 IEEE Power and Energy Society General Meeting, Minneapolis, MN, pp. 1-6, 25-29 Jul. 2010

[5] M. Prodanović, K. De Brabandere, J. Van den Keybus, T. Green and J. Driesen, "Harmonic and reactive power compensation as ancillary services in inverter-based distributed generation", in IET Gener. Transm. Distrib., vol. 1, issue 3, pp. 432-438, 2007.

[6] F. Hassan and R. Critchley, "Ancillary services of VSC interfaced energy sources - voltage harmonics compensation", in Proc. $5^{\text {th }}$ IET International Conf. Power Electronics, Machines and Drives PEMD 2010, Brighton, UK, pp. 1-6, 19-21 Apr. 2010.

[7] P. Mattavelli, and F.P. Marafao, "Repetitive-based control for selective harmonic compensation in active power filters", in IEEE Trans. Ind. Electron., vol. 51, no. 5, pp. 1018-1024, Oct. 2004

[8] J. M. Carrasco, L. G. Franquelo, J. T. Bialasiewicz, E. Galván, R. C. Portillo Guisado, M. A. Martín Prats, J. I. León, and N. Moreno-Alfonso, "Power-electronic systems for the grid integration of renewable energy sources: a survey", in IEEE Trans. Ind. Electron., vol. 53, no. 4, pp. 1002-1016, Aug. 2006.

[9] N. Femia, G. Petrone, G. Spagnuolo, and M. Vitelli, "A technique for improving P\&O MPPT performances of double-stage grid-connected photovoltaic systems", in IEEE Trans. Ind. Electron., vol. 56, no. 11, pp. 4473-4482, Nov. 2009.

[10] L. Piegari and P. Tricoli, "A control algorithm of power converters in smart-grids for providing uninterruptible ancillary services", in Proc. $14^{\text {th }}$ International Conference on Harmonics and Quality of Power ICHQP 2010, Bergamo, Italy, pp. 1-7, 26-29 Sep. 2010.

[11] A. Andreotti, A. Del Pizzo, R. Rizzo, and P. Tricoli, "An efficient architecture of a PV plant for ancillary service supplying", in International Symp. Power Electronics Electrical Drives Automation and Motion SPEEDAM 2010, Pisa, Italy, pp. 678-682, 14-16 Jun. 2010.

[12] F. Hassan and R. Critchley, "A robust PLL for grid interactive voltage source converters" in Proc. $14^{\text {th }}$ International Power Electronics and Motion Control Conf. EPE-PEMC 2010, Ohrid, Macedonia, pp. T2-29-T2-35, 6-8 Sept. 2010.

[13] P. Vas, Vector Control of AC Machines, Clarendon, Oxford (1990). 